\title{
Students' Expression of Attitude on Covid-19-Related Composition: A Study on Martin and White's Appraisal System
}

\author{
Laily Maulida Septiana Harti ${ }^{*}$, Kurniawati ${ }^{2}$ \\ ${ }^{1}$ Faculty of Languages and Arts, Universitas Negeri Surabaya, Indonesia \\ ${ }^{2}$ Faculty of Humanities, Universitas Airlangga, Surabaya, Indonesia \\ *Corresponding author.Email: lailyharti@unesa.ac.id
}

\begin{abstract}
This study investigates Attitude, one of the sub-system of Appraisal, in the students' expository writing, especially on Covid-19-related topic. Seven student compositions from Expository and Analytical Writing course conducted in a state university in Surabaya were selected purposefully to undergo the analysis. To evaluate students' feelings and emotion regarding the pandemic conveyed in their compositions, Appraisal theory by Martin and White (2005), an analytical framework within the Systemic Functional Linguistics (SFL) for interpersonal meanings, is used as reference. The analysis focuses on Affect, Judgment, and Appreciation which are realized through students' choice of attitudinal lexis. Affect is found to be used by students rather than the other two attitudinal lexis. Pedagogical implication to bettering the English writing instruction in EFL context, especially from an interpersonal perspective, of both linguistic and socio-cultural viewpoint are hoped to be exhorted from this study.
\end{abstract}

Keywords: Attitude, students' writing, Covid-19 topic, Appraisal

\section{INTRODUCTION}

Writing is one of the language skills that has primary function as the medium for author-audience communication. This means not only expressing one's opinion or ideas and attitude upon particular matter, author also in position to construct alignment and solidarity with their targeted audiences [1]. Writing is one of the communication tools that have an essential role for academician. In writing, students can deploy the result of their learning process, inform others about the current issues, and provide their invention to another academician. Through writing, thus, they can learn the experience to get more improvement in the study. Writing in a foreign language context is challenging for students [2], making it an important yet difficult to be acquired, especially in the second/foreign language context, as it is built upon many metacognitive processes [3]. Students need to work with the content, organization, language used, the writing conventions like the mechanics of spelling, punctuation, capitalization, and paragraphing, as well as other linguistic knowledge. As the main function is to provide a medium for author-audience communication, students need to master not only the grammatical competence and the language features according to the generic structure of the text they aim to write as mentioned earlier, but also the interpersonal meaning within the language they used in their writing.

Students' use of interpersonal meaning in their academic writing could pose a considerable challenge to non-native English speaker [4]. Researches in analyzing the students' attitude in second language writing using Appraisal system have been conducted in many contexts to provide facts $([5][6][7][8][9])$. On [8], a contrastive study of attitudinal meaning between students' Chinese and English composition aiming at observing the different use of attitudinal meaning due to the students' proficiency level and the difference between Chinese and English writing rhetoric was observed. Providing data on appraisal study from Indonesian context, [6] found that most students were using repetitive basic English words in expressing their attitude in their writing. Accordingly, this paper aims to uncover the current situation on the students' reservoir of evaluative words shown from their piece of writings.

\section{METHODS}

Working with students' piece of writings in analysing their expression of attitude, a qualitative method is employed to gain objective and specific result. There were a total of 37 students in the Expository and Analytical Writing course that the researcher was 
attended to. The course was attended by the freshman students in 2019/2020 academic year at a state university in Surabaya. Among the total of 37 compositions, seven compositions having Covid-19 as the theme were purposefully selected to further be analyzed using Martin and White's Appraisal system [10] in order to explore the students' ability in selecting and using appropriate words to express their attitude on Covid-19 related composition. In Appraisal system, there are three subsystems of Attitude, Engagement, and Graduation. In this paper, authors will only focus on Attitude as the major subsystem in Appraisal framework because it functions as the superordinate term for evaluative language in attitudinal positioning in text. Attitude is comprised of Affect, Judgement, and Appreciation which are expressed by the writer through selection of lexical choices. Thus, in analyzing students' composition, the paragraphs are divided into single clauses. The single clauses are then identified and categorized according to Martin and White's Appraisal system.

\section{RESULTS AND DISCUSSION}

The findings on the identification and categorization of the clauses showing students' attitude in their compositions are presented in Table 1. To guide, $\mathrm{T}$ stands for Text. The detailed frequency of the use of the attitudinal meaning of Affect, Judgement, and Appreciation in seven texts is shown in Table 1.

Table 1. Distribution of Attitude in the Texts

\begin{tabular}{|l|l|l|l|l|l|l|l|l|l|}
\hline \multirow{2}{*}{ Attitude } & T1 & T2 & T3 & T4 & T5 & T6 & T7 & \multicolumn{2}{|c|}{ Total } \\
\cline { 2 - 11 } & Freq & Freq & Freq & Freq & Freq & Freq & Freq & Freq & \% \\
\hline Affect & 4 & 4 & 6 & 3 & 6 & 2 & 2 & 27 & 51 \\
\hline Judgement & 3 & 3 & 2 & 3 & 2 & 4 & 2 & 19 & 35.8 \\
\hline Appreciation & 1 & 0 & 0 & 1 & 2 & 2 & 1 & 7 & 13.2 \\
\hline \multicolumn{1}{|c|}{ Total } \\
\hline
\end{tabular}

Table 1 shows the predominance of Affect as attitudinal meaning in their Covid-19 themed compositions (51\%). This is followed by Judgement and Appreciation, showing the number of $35.8 \%$ and $13.2 \%$ respectively. It is imperative to note that the students' composition are expository and analytical, in which they need to state fact, while being argumentative was yet to be the focus of the writing. This explanatory nature may provide reasoning as to why the number of attitudinal meaning employed in their writing is somewhat low.

\subsection{Appraising values of Affect}

Detail on the distribution of Appraising values of Affect shown in students' composition can be seen in Table 2 .
Table 2. Appraising Values of Affect

\begin{tabular}{|l|c|c|c|c|c|c|c|c|c|}
\hline \multirow{2}{*}{ Types } & T1 & T2 & T3 & T4 & T5 & T6 & T7 & \multicolumn{2}{|c|}{ Total } \\
\cline { 2 - 10 } & Freq & Freq & Freq & Freq & Freq & Freq & Freq & Freq & \% \\
\hline Insecurity & $\mathbf{2}$ & $\mathbf{2}$ & $\mathbf{3}$ & $\mathbf{1}$ & $\mathbf{2}$ & $\mathbf{1}$ & $\mathbf{1}$ & $\mathbf{1 2}$ & $\mathbf{4 4 . 4}$ \\
\hline Dissatisfaction & $\mathbf{1}$ & $\mathbf{1}$ & $\mathbf{0}$ & $\mathbf{1}$ & $\mathbf{4}$ & $\mathbf{1}$ & $\mathbf{1}$ & $\mathbf{9}$ & $\mathbf{3 3 . 3}$ \\
\hline Inclination & $\mathbf{0}$ & $\mathbf{1}$ & $\mathbf{2}$ & $\mathbf{0}$ & $\mathbf{0}$ & $\mathbf{0}$ & $\mathbf{0}$ & $\mathbf{3}$ & $\mathbf{1 1 . 1 5}$ \\
\hline Unhappiness & $\mathbf{1}$ & $\mathbf{0}$ & $\mathbf{1}$ & $\mathbf{1}$ & $\mathbf{0}$ & $\mathbf{0}$ & $\mathbf{0}$ & $\mathbf{3}$ & $\mathbf{1 1 . 1 5}$ \\
\hline \multicolumn{8}{|c|}{ Total } \\
\hline
\end{tabular}

Affect is the subcategories of Attitude that marks the emotional response towards particular person, thing, event, or state of affairs that is realized through lexical items such as verb as emotion, adjective and adverb of emotion, and nominalization [10]. The findings in Table 2 indicate that students make use of Insecurity, showing the negative feeling of peace and anxiety in regards to the Covid-19 situation. Samples from students' composition are provided below.

[T1] "for those who are accustomed to face to face learning will feel alienated, burdened and stress." - insecurity

[T2] "many Indonesian citizens angry and criticized the policy..." - insecurity

[T7] "Investors were also worried about the coronavirus that has attacked the stock market." - insecurity

[T4] "This policy makes student feels overwhelmed" dissatisfaction

[T5] "social distancing may cause boredom since we just stay at home" - dissatisfaction

[T6] "Some fans might feel disheartened by all these cancellations" - unhappiness

It is expected that the students would employ negative attitudinal lexis in their composition about Covid-19 through the selection of direct realization as shown from the abovementioned excerpts. However, in one student, it is found that indirect realization is being employed as seen below.

[T3] " a Chinese-German woman was assaulted by her neighbor spraying disinfectant while screaming "Corona" at her and threatening to cut her head off",

[T3] "they became stranded in a fight"

[T3] "A demonstration was also held in Bukittinggi to reject tourists from China."

The selection of indirect realization through Ideational meanings are aimed to invoke evaluation [10], even when the attitudinal lexis which tells the reader directly how to feel about the emergence of Coronavirus is absent. The discrepancy between the students' choice in employing direct and indirect realization is unique and thus worth further exploration. 


\subsection{Appraising values of Judgement}

Table 3 displays the detail on the distribution of Appraising values of Judgement shown in students' composition.

Table 3. Appraising Values of Judgement

\begin{tabular}{|l|c|c|c|c|c|c|c|c|c|}
\hline \multirow{2}{*}{ Types } & T1 & T2 & T3 & T4 & T5 & T6 & T7 & \multicolumn{2}{|c|}{ Total } \\
\cline { 2 - 11 } & Freq & Freq & Freq & Freq & Freq & Freq & Freq & Freq & \% \\
\hline Normality & $\mathbf{0}$ & $\mathbf{0}$ & $\mathbf{0}$ & $\mathbf{0}$ & $\mathbf{1}$ & $\mathbf{1}$ & $\mathbf{1}$ & $\mathbf{3}$ & $\mathbf{1 5 . 8}$ \\
\hline Capacity & $\mathbf{2}$ & $\mathbf{1}$ & $\mathbf{1}$ & $\mathbf{2}$ & $\mathbf{1}$ & $\mathbf{1}$ & $\mathbf{1}$ & $\mathbf{9}$ & $\mathbf{4 7 . 4}$ \\
\hline Tenacity & $\mathbf{0}$ & $\mathbf{1}$ & $\mathbf{0}$ & $\mathbf{1}$ & $\mathbf{0}$ & $\mathbf{0}$ & $\mathbf{0}$ & $\mathbf{2}$ & $\mathbf{1 0 . 5}$ \\
\hline Veracity & $\mathbf{1}$ & $\mathbf{0}$ & $\mathbf{1}$ & $\mathbf{0}$ & $\mathbf{0}$ & $\mathbf{1}$ & $\mathbf{0}$ & $\mathbf{3}$ & $\mathbf{1 5 . 8}$ \\
\hline Propriety & $\mathbf{0}$ & $\mathbf{1}$ & $\mathbf{0}$ & $\mathbf{0}$ & $\mathbf{0}$ & $\mathbf{1}$ & $\mathbf{0}$ & $\mathbf{2}$ & $\mathbf{1 0 . 5}$ \\
\hline \multicolumn{8}{|c|}{ Total } \\
\hline
\end{tabular}

Judgment is the attitudinal evaluation of human or organization body by referring to social norms [10]. This evaluation can be positive or negative. As observed from Table 3, the Judgement of Capacity value places first. Most of the Judgement are directed to the government that is expected to act in a certain way to handle the pandemic. Sample excerpts from students' writing can be seen below.

[T1] "The government hasn't been able to find a solution to the downturn crisis" - capacity

[T4] "... the airport screening tools look undependable to them"-tenacity

The use of inscribed negative judgment on the topic is expected. However, it is found that one student make use of positive judgement as seen as follow.

\section{[T2] "Yet, not all the effects of the coronavirus are bad." - propriety}

By further mentioning several positive effect the pandemic brought, this the student writer tries to invoke positive judgement on the readers; inviting the readers to think the same way as the author does. This viewpoint is considered fresh and anti-mainstream as this particular writing provides slightly different perspective than the rest of the composition submitted.

\subsection{Appraising values of Appreciation}

Detail on the distribution of Appraising values of Appreciation shown in students' composition can be seen in Table 4.

Table 4. Appraising Values of Appreciation

\begin{tabular}{|l|l|l|l|l|l|l|l|l|l|}
\hline \multirow{2}{*}{ Attitude } & T1 & T2 & T3 & T4 & T5 & T6 & T7 & \multicolumn{2}{|c|}{ Total } \\
\cline { 2 - 10 } & Freq & Freq & Freq & Freq & Freq & Freq & Freq & Freq & \% \\
\hline Reaction & 0 & 0 & 0 & 0 & 2 & 2 & 0 & 4 & 57 \\
\hline Composition & 0 & 0 & 0 & 1 & 0 & 0 & 0 & 1 & 14.4 \\
\hline Valuation & 1 & 0 & 0 & 0 & 0 & 0 & 1 & 2 & 28.6 \\
\hline \multicolumn{10}{|c|}{ Total } \\
\hline
\end{tabular}

Appreciation is positive or negative aesthetical evaluation for objects, things, or events [10]. From Table 4 , the students make use of Reaction in regards to the impact of Covid-19 pandemic. Samples from students' composition are provided below.

[T5] "We know that when this virus attacks Indonesia and spreads rapidly in several regions in Indonesia many dramatic changes occur in Indonesia" - Reaction

[T6] “... the school from home has been ineffective as students only be burdened with piles of homework from lecturer" - valuation

\subsection{Students' Expression of Attitude}

As displayed on table 1, students make use of Affect to disclose their personal emotion on the current situation of the pandemic. In detail, it is insecurity and dissatisfaction placed the first and the second simultaneously. The choice of direct and indirect realization are evidenced in their writing, marking the difference in their metacognitive process as they are working on their composition [3]. In detail, [3] mentions "effective selection of strategies and allocation of resources" play part in the writing process. This includes the students' metacognitive knowledge about themselves as the author, whose composition might have power to influence the readers. In addition, they have the control over topic selection that they choose to write, which should reflect their topic knowledge according to, for instance, their involvement or self-experience.

As far as Attitude is concerned, a question remains of whether the use of attitudinal lexis indicates their linguistic repertoire of appraisal resources for expressing their Attitude towards the Covid-19 topic. If this is the case, then teachers need to create the culture of learning in which the students can grow and expand their literacy on L2 writing, especially relating to Interpersonal meaning in displaying their engagement with the readers, particularly in expressing their Attitude as the author. [8] concludes that the difference in culture, between L1 and L2 writing rhetoric can contribute to their linguistic repertoire. In detail, the teaching of writing could, for example, focus on the rhetoric or genre of the text and introduce various attitudinal lexis to add to students' linguistic repertoire. Providing students with some knowledge and efficient writing strategies will help students to improve their writing.

In addition, in the study by [11], gaining some information from other skills will lead into certain complexity in students' writing. In the classroom setting, this can be executed by employing reading and speaking to writing course, so that students can have a better 
opportunity to practice expressing their attitude on a particular topic.

\section{CONCLUSION}

Drawing on Appraisal Theory, this present study finds the students' composition contains a variety of attitudinal markers with Affect constituting the highest percentage; Affect values pinpoint the insecurity and dissatisfaction of the student writer about the topic discussed. This patterns should be interpreted as a prelude rather than a generalization due to several explanatory nature. Firstly, the student writers were in the second semester of their undergraduate studies, in which their use of appraisal resources might develop as their proficiency increases. Secondly, school needs to create writing practices through the establishment of small culture - culture of learning - that provides opportunities for students' L1 literacy and their L2 cognitive strategies in composing L2 writing. Finally, it is deemed important to keep track on the students' development in L2 writing in various topics to expose students' use of evaluative language in their composition.

\section{REFERENCES}

[1] G. Thompson, "Interaction in academic writing: Learning to argue with the reader," Appl. Linguist., vol. 22, no. 1, pp. 58-78, 2001.

[2] S. Abdulwahed Ahmed Ismail, "Exploring Students' Perceptions of ESL Writing," English Lang. Teach., vol. 4, no. 2, p. 73, 2011.

[3] Y. Knospe, "Metacognitive Knowledge about Writing in a Foreign Language," in Metacognition in Language Learning and Teaching, Routledge, 2018, pp. 121-138.

[4] K. Hyland, "Patterns of engagement: dialogic features and L2 undergraduate writing" in Analysing Academic Writing: Contextualized Frameworks, London: Continuum, 2004, pp. 523.

[5] Y. Yang, "Appraisal Resources in Chinese College Students' English Argumentative Writing," J. Lang. Teach. Res., vol. 7, no. 5, p. 1002, 2016.

[6] S. W. Fitriati, Y. A. Solihah, and T. Tusino, "Expressions of Attitudes in Students' Narrative Writing: An Appraisal Analysis," Ling. Cult., vol. 12, no. 4, p. 333, 2018.
[7] G. Lv, "Appraisal Patterns in Chinese EFL Argumentative Essays," Theory Pract. Lang. Stud., vol. 5, no. 4, p. 818, 2015.

[8] X. Liu, "Evaluation in Chinese university EFL students' English argumentative writing: An APPRAISAL study," Electron. J. Foreign Lang. Teach., vol. 10, no. 1, pp. 40-53, 2013.

[9] M. Mori, "Using the Appraisal framework to analyze source use in essays: a case study of engagement and dialogism in two undergraduate students' writing," Funct. Linguist., vol. 4, no. 1, 2017.

[10] J. R. Martin and P. R. R. White, The Language of Evaluation: Appraisal in English. New York: Palgrave Macmillan, 2005.

[11] B. H. Tan, "Innovating writing centers and online writing labs outside north America," Asian EFL J., vol. 13, no. 2, pp. 390-417, 2011. 